SCIENTIFIC REPORT

\section{Finger's "slotted" eye plaque for radiation therapy: treatment of juxtapapillary and circumpapillary intraocular tumours}

\section{Paul T Finger}

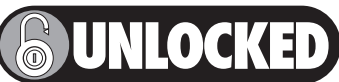

This paper is freely available online under the BMJ Journals unlocked scheme, see http://bjo.bmi.com/info/unlocked.dtl
Aim: To create "slotted eye plaques" for the treatment of juxtapapillary and circumpapillary intraocular tumours.

Methods: Eye plaques were altered such that $8 \mathrm{~mm}$-wide slots (variable length) were created to accommodate the orbital portion of the optic nerve. Thus, as the nerve entered the slot, the plaque's posterior margin extended beyond the optic disc. Radioactive seeds were affixed around the slot, surrounding the juxtapapillary and posterior tumour margins.

Results: As proof of principle, three patients with choroidal melanomas that encircled or were in contact with the optic disc (considered untreatable with a notched eye plaque) were considered to be initial candidates for slotted-plaque radiotherapy. Preoperative three-dimensional C-scan imaging of their optic nerve sheath diameters insured that they would fit in the slotted plaque. Intraoperative ultrasound imaging was used to confirm proper plaque placement. Radiation dosimetry modelling showed that all tumour tissue received a minimum of $85 \mathrm{~Gy}$ (despite the gap created by the slot). With relatively short-term follow-up, there has been no evidence of ocular ischaemia, tumour growth or complications attributable to the use of slotted-plaque radiation therapy.

Conclusion: Slotted plaques accommodate the retrobulbar optic nerve into the device and thereby shift the treatment zone to improve coverage of both juxtapapillary and circumpapillary intraocular tumours.

$\mathrm{R}$ adioactive eye plaques are typically positioned on the sclera to cover the intraocular tumour base and a $2-3 \mathrm{~mm}$ free margin of normal-appearing tissue. ${ }^{12}$ However, this is not possible in treatment of tumours that touch or surround the optic disc. ${ }^{1}$ This is because the optic nerve exits the posterior aspect of the globe, creating an obstacle to proper plaque placement. In addition, the retrobulbar optic nerve sheath diameter is typically three times that of the optic disc diameter. ${ }^{3}$ Therefore, even when a notched plaque is perfectly placed against the optic nerve sheath, the plaque's posterior edge is likely to be at least $1.7 \mathrm{~mm}$ anterior to the optic disc and juxtapapillary tumour interface.

Despite this anatomical handicap, plaque radiation therapy has offered local control of selected juxtapapillary tumours..$^{5-7}$ In these cases, plaque notching, radiation side-scatter and posterior "plaque tilting" have been suggested as factors that allow successful treatment. ${ }^{1}$ Intraoperative ultrasonographic or specialised plaque-localisation techniques are recommended. ${ }^{8-11}$ However, most eye cancer specialists will currently recommend enucleation or external beam irradiation of eyes with tumours in contact with $\geqslant 180^{\circ}$ of the optic disc. ${ }^{12-16}$ Plaque radiation therapy for tumours that touch or surround the optic disc continues to be a clinical challenge. ${ }^{1}$

This study demonstrates how juxtapapillary and even circumpapillary tumours can be treated with radioactive plaques. Finger's "slotted"-plaque design reduces the probability of geographical miss by allowing the entire optic nerve (and a $2 \mathrm{~mm}$ free margin of safety) to be incorporated beneath the plaque.

\section{MATERIALS AND METHODS \\ Plaque construction}

The goal of slotted-plaque construction was to incorporate at least a portion of the retrobulbar optic nerve within the plaque. Plaque shells were altered to create an $8 \mathrm{~mm}$-wide (transverse diameter) slot at their posterior margin (fig 1). The depth (longitudinal diameter) of the slot was modulated to include the tumour and a 2-3 mm margin of normal-appearing tissue beyond its posterior margin.

Table 1 and figure 2 demonstrate four hypothetical tumours with varying degrees of involvement of the optic disc. Comparative dosimetry was performed to estimate the relative dose distributions to the tumour, centre of the optic nerve and fovea using palladium$103\left(\mathrm{Pd}^{103}\right)$, iodine-125 $\left(\mathrm{I}^{125}\right)$ and ruthenium-106 $\left(\mathrm{Ru}^{106}\right)$. When possible, a nasal approach will decrease irradiation of the fovea. Calculations were performed and images created using the Plaque Simulator Software Program (Bebig, Berlin, Germany).

\section{CALCULATION OF SLOT DEPTH \\ Optic nerve sheath distance}

Optic nerve sheath distance is defined as the (anteriorposterior) distance between the horizontal edge of the optic disc and the optic nerve sheath. For example, optic nerve sheath distance can be estimated based on a mean $5 \mathrm{~mm}$ optic nerve sheath diameter-a mean $1.63 \mathrm{~mm}$ ( 1.5 horizontal or 1.75 vertical) optic disc diameter divided by $2=1.7 \mathrm{~mm}$.

\section{Slot depth calculation}

Using this $1.7 \mathrm{~mm}$ optic nerve sheath distance, add $0.75 \mathrm{~mm}$ (half the horizontal optic disc diameter) and a $3.0 \mathrm{~mm}$ (tumour-free margin) and a measured millimetre value of tumour extension beyond the disc midline $=$ slot depth.

\section{HYPOTHETICAL EXAMPLE}

A calculation used to decide the slot depth for treatment of a tumour in contact with $180^{\circ}$ of the optic disc could be approximated as follows: $1.7 \mathrm{~mm}$ (optic nerve sheath distance) and $0.75 \mathrm{~mm}$ (half-thickness of optic disc because of $180^{\circ}$ perineural tumour extension) and $3.0 \mathrm{~mm}$ of additional posterior margin. Simple addition results in a $5.5 \mathrm{~mm}$ slot depth (depending on the preferred amount of tumour-free posterior margin).

In practice, the actual optic disc and optic nerve sheath diameter were measured with fundus photography and threedimensional ultrasound C-scan techniques. ${ }^{3}$ For ease of plaque insertion (access to the plaque eyelets), at least $10 \mathrm{~mm}$ of plaque diameter was retained from the apex of the slot, along the longitudinal axis towards the anterior margin 

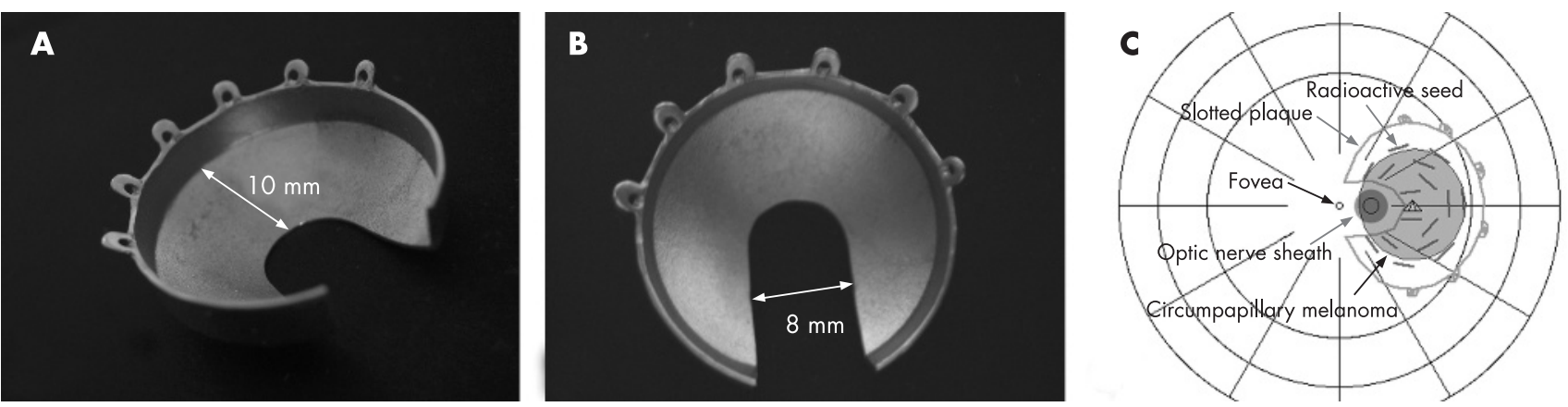

Figure 1 Finger's slotted eye plaque radiation therapy: External photographs (A, B) reveal two perspectives of an $18 \mathrm{~mm}$ slotted plaque. This slotted plaque retains a $10 \mathrm{~mm}$ longitudinal plaque diameter from the slot apex to the anterior "eyelet" margin. It also contains an $8 \mathrm{~mm}$-wide slot for the optic nerve. (C) This diagram shows how the plaque can be placed to incorporate the optic nerve and extend beyond the posterior margin of a minimally circumpapillary intraocular tumour. This image was created using the Plaque Simulator Software Program (Bebig, Berlin, Germany).

Table 1 Finger's slotted plaque radiation therapy

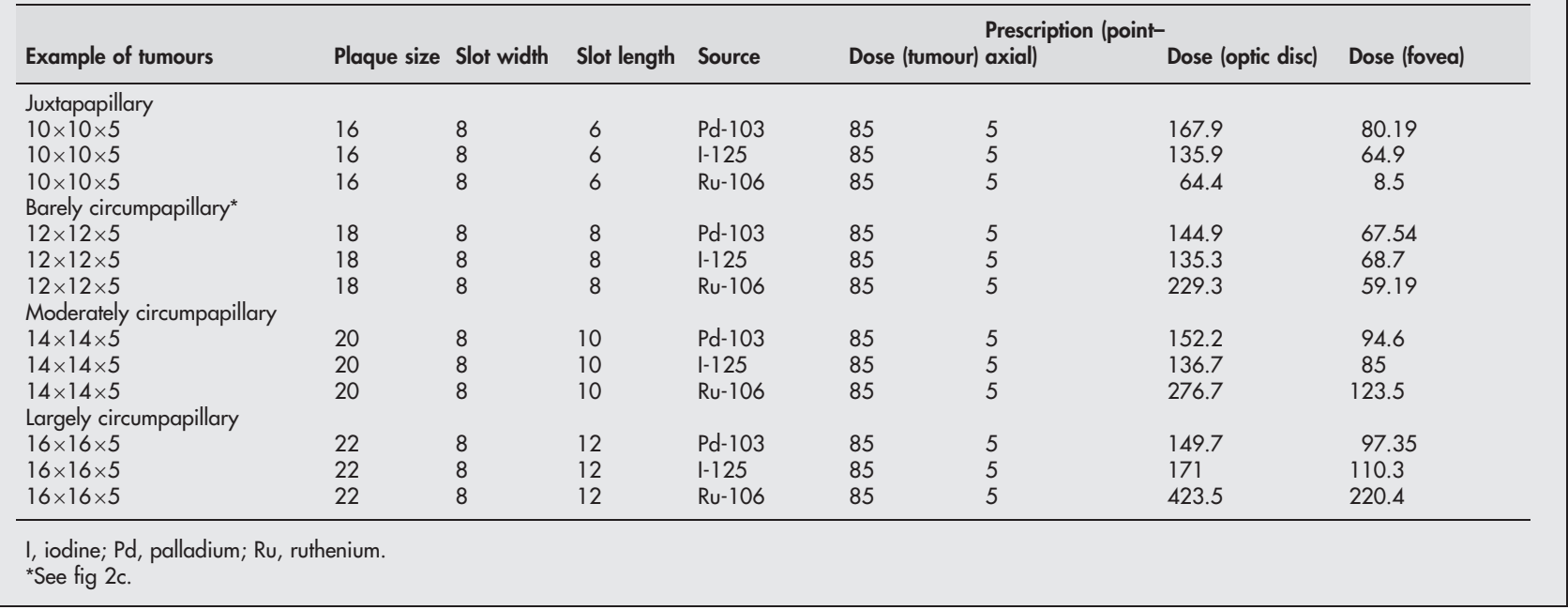
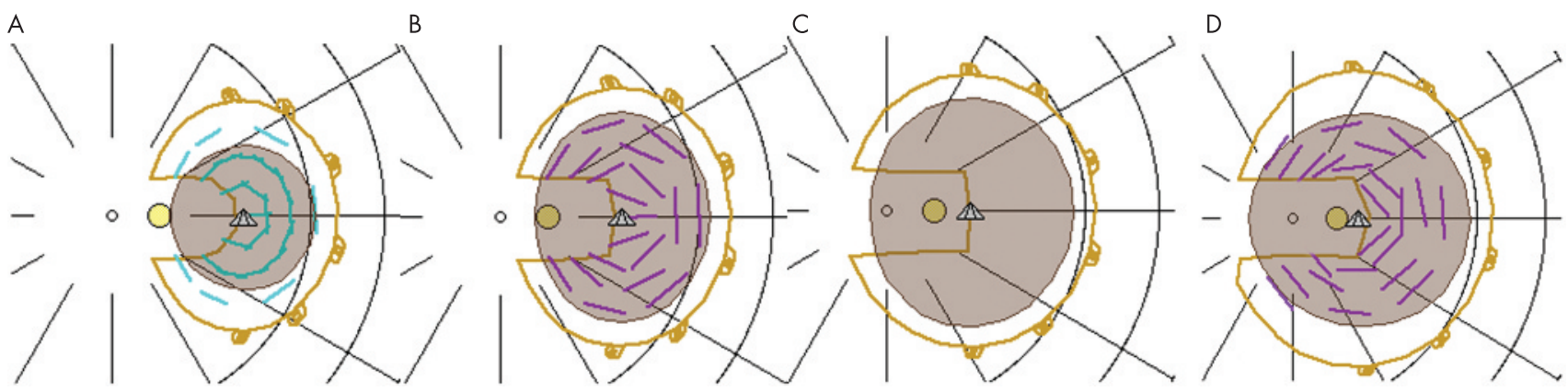

Figure 2 Calculation of slot depth.

and eyelets (fig 1). These requirements limited plaque diameters to $>16 \mathrm{~mm}$ (table 1 ).

Slot depth+10 $\mathrm{mm}=$ overall plaque diameter

\section{Slotted-plaque dosimetry}

To maximise the tumour dose and minimise irradiation of normal ocular structures, radioactive seeds were manually affixed within the plaque. The distribution of radioactive seeds was adjusted to conform to tumour size and location and to compensate for the gap created by the slot. Seed locations were documented and digitised. In this series, a minimum tumour dose of $85 \mathrm{~Gy}$ was prescribed to an axial depth of $\geqslant 5 \mathrm{~mm}$.
Thus, the prescription point (at depth) can be modulated to provide a minimum tumour tissue dose.

For illustration, dosimetry is presented using the Plaque Simulator Program; radiation dosimetry simulations were performed to compare the dose distributions provided by slotted-plaque designs (using $\mathrm{Pd}^{103}, \mathrm{I}^{125}$ or $\mathrm{Ru}^{106}$ ) (table 1). ${ }^{17-19}$

\section{Plaque insertion}

Slotted eye plaques can be inserted much like other eye plaques. However, temporary disinsertion of both rectus and oblique muscle was more probably required (two of three cases). Owing, in part, to juxtapapillary positioning and posterior 
edges, slotted plaques were gently placed to straddle the retrobulbar optic nerve. Intraoperative three-dimensional ultrasonography was used to confirm plaque placement (fig 3). ${ }^{8}$

\section{Case selection}

This study conformed to the Declaration of Helsinki and the United States Health Insurance Portability and Privacy Act of 1996. In this series, the relative risks and potential benefits of observation, radiation (eg, plaque, proton) and enucleation were discussed. Each patient was informed about the number of patients previously treated and chose slotted radioactive plaque therapy.

Case selection and informed consent brought focus on the choice between the potential for vision versus local tumour control. It seemed reasonable to assume that posterior migration of the plaque's targeted zone (around the optic disc) would increase the incidence of radiation optic neuropathy and the risk of vision loss. However, external beam techniques include more of the optic nerve. When compared with enucleation, all radiation therapy techniques offer some potential for vision retention. Our initial case selection included only those tumours that were not treatable with notched radioactive plaques.

\section{RESULTS}

Slotted plaques were constructed and used to deliver brachytherapy for the treatment of three patients with intraocular tumours. These included two choroidal melanomas that completely encircled (circumpapillary) and one that was in contact with $>180^{\circ}$ (juxtapapillary) of the optic disc.

\section{Illustrative case}

A 33-year-old woman presented with a choroidal melanoma that had encircled (circumpapillary) and displaced the optic disc (fig 4). An $18 \mathrm{~mm}$ gold plaque was carved to create an $8 \mathrm{~mm}$-wide and $8 \mathrm{~mm}$-deep slot at its posterior margin. Slot creation eliminated a portion of the posterior sidewall (fig 1). Radioactive seeds were individually placed and affixed (with acrylic) within the plaque, including at positions adjacent to the slot. Once surgically placed, the plaque encircled the optic nerve and covered the entire circumpapillary melanoma and a posterior tumour-free margin. Intraoperative three-dimensional ultrasound imaging confirmed proper plaque placement (fig 3). Preoperative radiation dosimetry confirmed that the tumour received in excess of the minimum tumour dose of 85 Gy.
This patient has been followed up for 16 months. To date, there has been no evidence of tumour growth or complications necessitating secondary treatment. ${ }^{20}$ She has lost two lines of visual acuity, with a best corrected Early Treatment Diabetic Retinopathy Study vision of 20/32. Tumour regression has been documented with fundus photography, angiography and ultrasonography. The choroidal melanoma decreased in size and blood flow, with ultrasonographic documentation of tumour regression from 5.2 to $3.1 \mathrm{~mm}$ in apical height (fig 3).

Since this case, two additional patients have been treated with slotted-plaque radiation therapy. To date, no surgical or unusual radiation side effects could be attributed to the use of slotted plaques in these cases. Each tumour has responded to irradiation. Follow-up has been $<1$ year in each of these additional cases

\section{DISCUSSION}

Slotted-plaque radiation therapy is ideally suited for current low-energy $(21-28 \mathrm{keV})$ plaque techniques using $\mathrm{I}^{125}$ and $\mathrm{Pd}^{103}$. This is because the radioactive components of these plaques are rice grain-sized seeds whose strength and location can be modulated, conforming to the location and size of the tumour, plaque and slot. In contrast with slotted $\mathrm{I}^{125}$ and $\mathrm{Pd}^{103}$ eye plaques, $\mathrm{Ru}^{106}$ plaques are not designed to irradiate within the minimum $8 \mathrm{~mm}$-wide slot. While such a configuration might be possible, the manufacturer should only shape $\mathrm{Ru}^{106}$ eye plaques. Cutting into a $\mathrm{Ru}^{106}$ plaque would create a serious radiation-safety hazard.

In comparison to external beams (eg, radiosurgery, the $\gamma$ knife and proton beam), slotted-plaque therapy offers the most conformal tumour treatment (much less irradiation of normal anterior ocular and adnexal structures). For example, after stereotactic radiosurgery for juxtapapillary melanomas, Simpson et al reported short-term (18-month) actuarial rates of secondary neovascular glaucoma, cataract, retinopathy and optic neuropathy of $20 \%, 29 \%, 30 \%$ and $37 \%$, respectively. ${ }^{13}$ When compared with external-beam radiation therapy techniques, slotted-plaque therapy will deliver less radiation to both the anterior segment and the optic nerve (posterior to the plaque)..$^{13} 14$

This study demonstrates that slotted radioactive plaques can be used to create a "target" zone that includes the entire optic nerve head and adjacent intraocular tumour. This design improves our ability to match tumour and plaque location. In
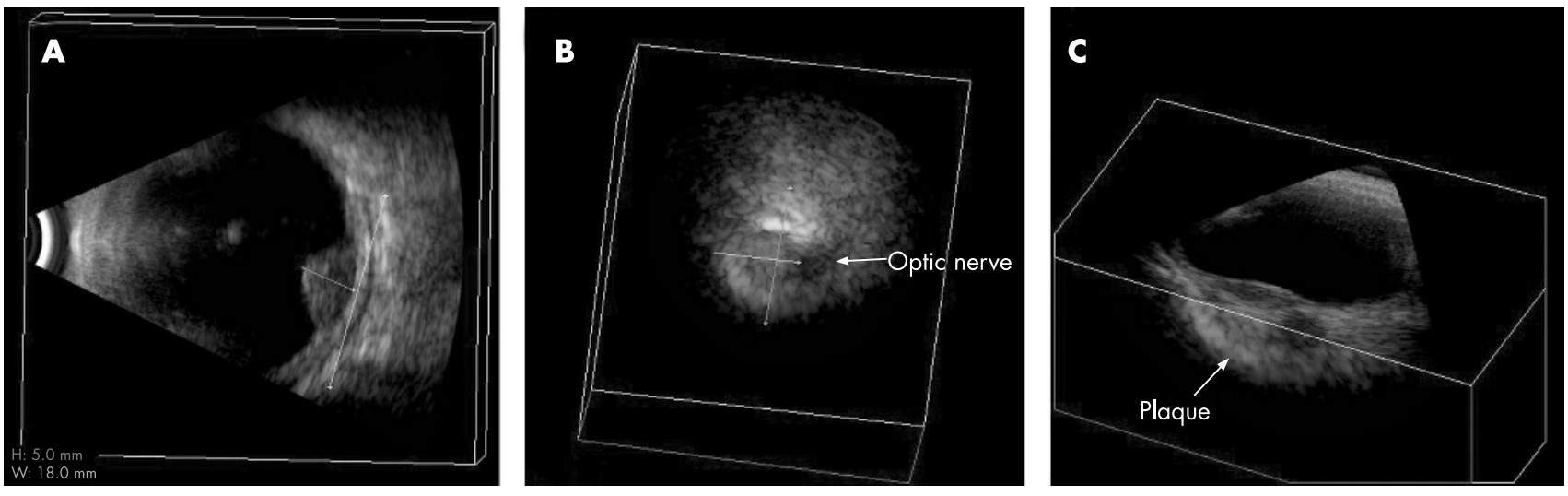

Figure 3 Finger's slotted-plaque radiation therapy. A series of intraoperative three-dimensional B-scan ultrasound (3DUS) reconstructions of patient 1. (A) The hyper-reflective eye plaque, delineated by the measurement cursor is seen to cover the longitudinal section of the tumour. (B) A two-dimensional coronal $\mathrm{C}$-scan reconstruction reveals the plaque in position, incorporating the echolucent optic nerve. (C) 3DUS reconstruction allows simultaneous C-scan coronal imaging of the plaque-optic nerve interface as well as the plaque centration over the tumour. 


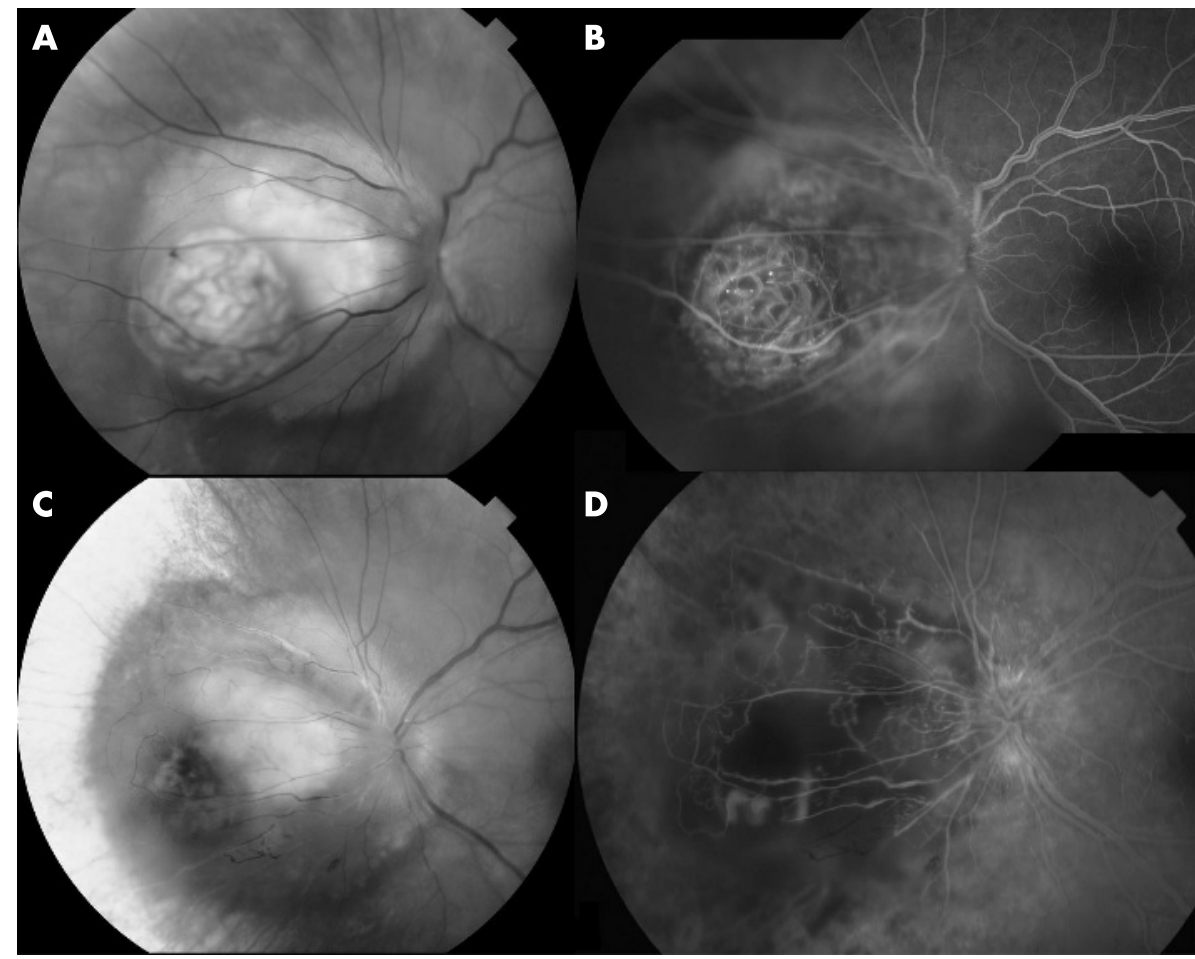

Figure 4 Finger's slotted-plaque radiation therapy. (A) Composite photographs demonstrating the pretreatment circumpapillary melanoma and its earlyphase fluorescein angiographic appearance. (B) Note the double circulation seen within its mushroom extension. (C) Sixteen months after slotted-plaque radiation therapy, the tumour is smaller, the mushroom extension is darkened and shrunken, and the optic nerve is less tilted. There is considerable chorioretinal atrophy along its anterior margin. (D) Corresponding fluorescein angiography reveals decreased tumour circulation, optic disc leakage and cystoid macular oedema.

this series, radiation dosimetry studies demonstrated that juxtapapillary and circumpapillary choroidal melanoma received at least the minimum (apical) tumour dose. Thus, Finger's slotted plaques could be considered as an alternative to external beam irradiation as well as an eye and vision-sparing alternative to enucleation for selected intraocular tumours that touch or surround the optic disc.

Funding: This clinical study was supported by The EyeCare Foundation, New York City, New York, USA.

Competing interests: None declared.

PTF has a United States Patent pending for a "Slotted Plaque Therapy Device".

Correspondence to: Dr P T Finger, The New York Eye Cancer Centre, 115 East 61 st Street, New York City, NY 10065, USA; pfinger@eyecancer.com

Accepted 1 February 2007

Published Online First 27 February 2007

\section{REFERENCES}

Finger PT. Radiation therapy for choroidal melanoma. Surv Ophthalmo 1997:42:215-32.

2 Finger PT, Murphree AL. Ophthalmic brachytherapy: treatment of choroidal melanoma and retinoblastoma. In: Peyman GA, Meffert S, Conway MD, Chou F, eds. Vitreoretinal surgical techniques. London: Martin Dunitz, 2001:403-18.

3 Garcia JP Jr, Garcia PT, Rosen RB, et al. A 3-dimensional ultrasound C-scan imaging technique for optic nerve measurements. Ophthalmology 2004;111:1238-43

4 Garcia JP Jr, Garcia PM, Rosen RB, et al. Optic nerve measurements by 3D ultrasound-based coronal "C-scan" imaging. Ophthalmic Surg Lasers Imaging 2005;36: 142-6.

5 Lommatzsch PK, Lommatzsch R. Treatment of juxtapapillary melanomas. Br J Ophthalmol 1991;75:715-17.
6 Packer S, Stoller S, Lesser ML, et al. Long-term results of iodine 125 irradiation of uveal melanoma. Ophthalmology 1992;99:767-74.

7 De Potter P, Shields CL, Shields JA, et al. Plaque radiotherapy for iuxtapapillary choroidal melanoma. Visual acuity and survival outcome. Arch Ophthalmol 1996; 114:1357-65.

8 Finger PT, Romero JM, Rosen RB, et al. Three-dimensional ultrasonography of choroidal melanoma: localization of radioactive eye plaques. Arch Ophthalmol 1998;116:305-12.

9 Harbour JW, Murray TG, Byrne SF, et al. Intraoperative echographic localization of iodine 125 episcleral radioactive plaques for posterior uveal melanoma. Retina 1996;16:129-34.

10 Finger PT, lezzi R, Esteveo ML, et al. Diode-light transillumination for ophthalmic plaque localization around juxtapapillary choroidal melanomas. Int J Radiat Oncol Biol Phys 1999;44:887-90.

11 Pavlin CJ, Japp B, Simpson ER, et al. Ultrasound determination of the relationship of radioactive plaques to the base of choroidal melanomas. Ophthalmology 1989:96:538-42

12 Hocht S, Stark R, Seiler F, et al. Proton or stereotactic photon irradiation for posterior uveal melanoma? A planning intercomparison. Strahlenther Onkol 2005;181:783-8.

13 Emara K, Weisbrod DJ, Sahgal A, et al. Stereotactic radiotherapy in the treatment of juxtapapillary choroidal melanoma: preliminary results. Int J Radiat Oncol Biol Phys 2004;59:94-100.

14 Char DH, Kroll S, Phillips TL, et al. Late radiation failures after iodine 125 brachytherapy for uveal melanoma compared with charged-particle (proton or helium ion) therapy. Ophthalmology 2002;109:1850-4.

15 Wilson MW, Hungerford JL. Comparison of episcleral plaque and proton beam radiation therapy for the treatment of choroidal melanoma. Ophthalmology 1999:106:1579-87.

16 Finger PT. "Finger-tip" cryoprobe assisted enucleation. Am J Ophthalmol 2005;139:559-61.

17 Astrahan MA. Improved treatment planning for COMS eye plaques. Int J Radiat Oncol Biol Phys 2005:61:1227-42.

18 Astrahan MA, Luxton G, Pu Q, et al. Conformal episcleral plaque therapy Int J Radiat Oncol Biol Phys 1997;39:505-19.

19 Astrahan MA, Szechter A, Finger PT. Design and dosimetric considerations of a modified COMS plaque: the reusable "seed-guide" insert. Med Phys 2005;32:2706-16.

20 Finger PT. Anti VEGF bevacizumab (Avastin ${ }^{\circledR}$ ) for radiation optic neuropathy. Am J Ophthalmol 2007;143:335-8. 